\title{
Continuity Theory of Ageing and Leisure Participation among Elderly Attending Selected Health Clinics in Selangor
}

\author{
Minhat $\mathrm{HS}^{\mathrm{a}}$, Rahmah $M \mathrm{~A}^{\mathrm{b}}$, Khadijah $\mathrm{S}^{\mathrm{b}}$ \\ ${ }^{a}$ Department of Community Health, Faculty of Medicine and Health Sciences, University Putra Malaysia \\ ${ }^{b}$ Department of Community Health, Faculty of Medicine and Health Sciences, Universiti Kebangsaan Malaysia
}

\begin{abstract}
Introduction: Leisure participation in old age is often a continuation of their participation at younger age. This study aims to explore the association between current and former leisure participation of the elderly. Methods: A cross-sectional survey was conducted among 268 persons aged 60 years and above, purposively selected from eight health clinics in Selangor. Current leisure participation was measured using a validated Leisure Participation Questionnaire (LPQ), specific for Malaysian elderly. The LPQ consists of 25 activities, categorized into recreational (physical), cognitive, social and productive activity. Frequency of participation in each activity was measured on a 6-point scale. Leisure participation at younger age only involved their general participation in leisure. The most common daily leisure activities were having conversations while relaxing (78.7\%) and watching television (74.6\%), while the least were from playing golf $(0.01 \pm 0.12)$ and performing musical instruments $(0.04 \pm 0.36)$. More than half $(64.9 \%)$ reported being actively involved in any leisure activity at younger age. Results: The study found there was a significant association between former and current leisure participation, especially for cognitive $(t=-2.45, p=0.015)$, social $(t=-2.68, p=0.008)$ and productive $(\mathrm{t}=-2.89, \mathrm{p}=0.004)$ activities. However, only productive activity involvement was predicted by their leisure participation while younger $(B=1.304, p=0.027)$. Conclusion: The findings suggest the importance of considering active intervention programmes at younger age to ensure better leisure participation of the elderly, especially in recreational physical activity.
\end{abstract}

\section{INTRODUCTION}

The ageing population phenomenon is spreading rapidly and has become one of the greatest challenges globally. Worldwide, the total number of elderly is expected to triple from 259 million in 1980 to 761 million by 2025 , in which $72 \%$ (236.9 million) will be from the developing countries. ${ }^{1}$ By $2050,80 \%$ of the 2 billion elderly people on this planet will live in the developing world. ${ }^{2}$ Countries in Asia are set to see some of the biggest rises-by 2050 , one in four Asians will be older than 60 years of age. ${ }^{2}$

Increasingly greying society has led to more focus given to the development of active and successful ageing population. One of the aspects that had gained considerable attention is leisure participation, especially among the gerontologists and leisure researchers. Studies have repeatedly reported the

Corresponding author:

Dr. Halimatus Sakdiah Minhat, Department of Community Health, Faculty of Medicine and Health Sciences,

Universiti Putra Malaysia, 43400 Serdang, Selangor, Malaysia.

Tel: +60123438175

Fax no: +60389450151

E-mail: aton75@yahoo.com various benefits of leisure participation among elderly. Studies have shown that the elderly populations that actively involved in leisure activities are more likely to have better quality of life and life satisfaction. ${ }^{3,4}$

Researchers also believe that there is a continuity pattern of the activities currently performed by the elderly with what they had done when they were younger. According to the Continuity Theory of Ageing, individuals do not really change as they age, but becoming more of what they have always been. ${ }^{5}$ Continuity Theory is a psychosocial theory of aging, which posits that as middle-aged and elderly adults adapt to changes associated with the normal aging process, their past experiences, decisions, and behaviors will form the foundation for their present and future decisions and behaviors. ${ }^{6}$

Maintaining patterns of thought, activities, and habits is the most common strategy for adaptation as people age. ${ }^{5}$ According to Atchley, ${ }^{7}$ Continuity Theory holds that, in making adaptive choices, middle-aged and older adults attempt to preserve and maintain existing internal and external structures; and they prefer to accomplish this objective by using strategies tied to their past experiences of themselves and their social world.

A study involving elderly aged 65 years and above in New York reported that, the elderly is more likely to actively involved in leisure, if such activity has been 
performed since young age. ${ }^{8}$ Solitary activities such as watching television and listening to the radio have been cited as the most popular pursuits among this age group, ${ }^{3,9}$ whereas sports and exercise programs are activities in which participation is least likely. ${ }^{10}$

In accordance with the Continuity Theory of Aging, leisure participation in old age is often a continuation of previous participation. This continuous pattern of participation does not only involve leisure activities, but also other domains of life. Although, continuity is a grand adaptive strategy that is promoted by both individual preference and social approval, ${ }^{7}$ it does not necessarily entail successful aging. ${ }^{5}$

Leisure is an indispensable domain of life for everybody at different ages. ${ }^{3}$ It implies time to relax and play and also engagement in desired activities without any obligation or duty. The activity engaged in is frequently associated with enjoyment and is independent of work or the activities of daily living. This paper aims to explore the association between current and former leisure participation of the elderly society and their associated socio demographic characteristics.

\section{MATERIALS AND METHODS}

\section{Study Setting}

Data for this cross-sectional study was collected in eight health clinics in 4 different districts in Selangor; namely Petaling, Klang, Hulu Langat and Kuala Langat.

\section{Study Population}

Malaysian citizens aged 60 years and above who utilized health services in the designated health clinics were selected purposively. All recruited elderly, were screened using the Elderly Cognitive Assessment Questionnaire (ECAQ) and the Geriatric Depression Scale (GDS). A total of 335 elderly people were screened initially. However, only elderly with a normal score for cognitive function and depression were included. Thus, 268 elderly were eligible to participate in this study.

\section{Questionnaire}

Eligible elderly were asked about their sociodemographic background using a standardized pretested questionnaire. They were also asked about their general involvement in leisure at younger age using a nominal scale, 'Yes' or 'No'. Respondents who answered 'Yes' were also requested to state the frequency of the activity performed. Meanwhile, current leisure participation was measured using a
Leisure Participation Questionnaire (LPQ), specifically constructed and validated for Malaysian elderly. The LPQ consists of 25 activities which were categorized into four categories namely, recreational, cognitive, social and productive activity based on the categories used in a study by Cheung et al. ${ }^{3}$ Recreational activity refers to physical form of recreational activity such as walking, running, cycling and any form of sports. Meanwhile, cognitive activity refers to activity that involves active information processing as a central component. Social activity refers to activity that promotes interpersonal interactions, developed social identity and regulated emotions. Productive activity involves organizing and performing the required tasks, providing services, or generating products. The measurement of leisure participation for both current and leisure at younger age was based on a 6-point Likert-scale. The scales used were everyday (5), almost everyday (4), once a week (3), once a month (2), once in few month (1) and never $(0)$.

\section{Statistical Analysis}

The data were analyzed using Statistical Package for Social Sciences (SPSS) version 19.0 software. The level of significance was set at 0.05. Student t-tests were performed to assess the association between general involvement in leisure while younger and current leisure participation of elderly in all four different categories of leisure activities. Religion was excluded in the regression analysis due to its similarity and interaction with ethnicity. This was followed by regression analyses of the predicting factors for each category of current leisure activity. Self-reported general involvement in leisure while younger and socio demographic factors other than religion were entered into the regression model.

\section{RESULTS}

\section{Characteristics of respondents}

The socio-demographic characteristics of the 268 elderly who were eligible and agreed to participate in this study are shown in Table I. The mean age of this sample was 67.65 years (range, 61-73 years). The majority were in the young-old group (84.7\%), Malays (71.6\%), living with others $(91.4 \%)$, married $(67.9 \%)$ and had only received primary education (60.8\%). Whereas, other factors such as gender, having no fixed income and place of residence either in rural or urban area were equally distributed among the respondents. On the other hand, $64.9 \%$ of the elderly reported that they generally participated in certain type of leisure activity when they were young. 
Table I. Characteristics of respondents $(n=268)$

Factors

Age (years)

$$
\text { young-old (60-74) }
$$$$
\text { old-old }(\geq 75)
$$

Gender

Male

Female

Ethnic

Malay
Chinese
Indian
Others

Religion

Islam

Buddha

Hindu

Others

Marital Status

Single

Married

Divorcee/widower/widow

Education Level

None

Primary school

Secondary school

College/University

Income

None

$<$ RM720

RM721 - RM1000

RM1001 - RM2000

$>\mathrm{RM} 2000$

Living Arrangement

Living alone

Living with others

Locality

Rural

Urban

General leisure participation while younger

Yes

174

94
50.0

$\%$

84.7

15.3

48.5

51.5

71.6

15.7

11.9

0.7

72.0

11.6

9.3

7.1

1.9

67.9

30.2

7.5

60.8

28.0

3.7

50.0

8.6

22.8

16.4

2.2

8.2

91.4

245

50.0

64.9

35.1

RM=Ringgit Malaysia

\section{Current leisure participation}

The distribution of leisure activity carried out by the elderly is reported in Table 2. Among the recreational physical activities, exercising was found to have the highest participation rate, while playing golf gives the lowest level of involvement. Sedentary activities such as watching television and reading were found to dominate the cognitive activities. On the other hand, having conversations while relaxing and spending time with grandchildren were the two most common social activities spent during leisure among the elderly. As for productive activity category, gardening was found to be the most frequently performed leisure activity. 
n (\%)

\begin{tabular}{|c|c|c|c|c|c|c|c|}
\hline \multirow{2}{*}{ Leisure Activity } & & & & & & & \\
\hline & $\begin{array}{l}\text { Everyday } \\
\text { (5) }\end{array}$ & $\begin{array}{l}\text { Almost everyday } \\
\text { (4) }\end{array}$ & $\begin{array}{l}\text { At least once a week } \\
\text { (3) }\end{array}$ & $\begin{array}{l}\text { At least once a month } \\
\text { (2) }\end{array}$ & $\begin{array}{l}\text { Once in several months } \\
\text { (1) }\end{array}$ & $\begin{array}{l}\text { Never } \\
(0)\end{array}$ & Mean $\pm S D$ \\
\hline \multicolumn{8}{|l|}{ Recreational Activity (RA): } \\
\hline $\begin{array}{l}\text { 1. Exercise (tai-chi, jogging, } \\
\text { walking, cycling etc) }\end{array}$ & $46(17.2)$ & $27(10.2)$ & $8(3)$ & $8(3)$ & $3(1.1)$ & $176(65.7)$ & $1.42 \pm 2.07$ \\
\hline $\begin{array}{l}\text { 2. Going for walks } \\
\text { (in the park etc) }\end{array}$ & $17(6.3)$ & $22(8.2)$ & $11(4.1)$ & $13(4.9)$ & $8(3)$ & $197(73.5)$ & $0.90 \pm 1.64$ \\
\hline $\begin{array}{l}\text { 3. Playing sports } \\
\text { (badminton, tennis etc) }\end{array}$ & $1(0.4)$ & $1(0.4)$ & $1(0.4)$ & $1(0.4)$ & $1(0.4)$ & $263(98.1)$ & $0.06 \pm 0.45$ \\
\hline \multicolumn{8}{|l|}{ Cognitive Activity (CA): } \\
\hline $\begin{array}{l}\text { 1. Reading (books/Quran/ } \\
\text { bible etc) }\end{array}$ & $170(63.4)$ & $44(16.4)$ & $15(5.6)$ & $20(7.5)$ & $8(3.0)$ & $11(4.1)$ & $4.18 \pm 1.38$ \\
\hline $\begin{array}{l}\text { 2. Playing cards, chess, } \\
\text { mahjong etc }\end{array}$ & $1(0.4)$ & $2(0.7)$ & $4(1.5)$ & $1(0.4)$ & $1(0.4)$ & $259(96.6)$ & $0.10 \pm 0.60$ \\
\hline $\begin{array}{l}\text { 3. Using computer/ } \\
\text { Browsing internet }\end{array}$ & $3(1.1)$ & $6(2.2)$ & - & $4(01.5)$ & $1(0.4)$ & $254(94.8)$ & $0.18 \pm 0.82$ \\
\hline $\begin{array}{l}\text { 4. Performing musical } \\
\text { instruments }\end{array}$ & - & $1(0.4)$ & $2(0.7)$ & - & - & $265(98.9)$ & $0.04 \pm 0.36$ \\
\hline $\begin{array}{l}\text { 6. Teaching (tuition/ } \\
\text { Quran classes) }\end{array}$ & $6(2.2)$ & $6(2.2)$ & $1(0.4)$ & $4(1.5)$ & - & $251(93.7)$ & $0.24 \pm 0.98$ \\
\hline 7. Watching TV & $200(74.6)$ & 47 (17.5) & $9(3.4)$ & $11(4.1)$ & $1(0.4)$ & - & $4.62 \pm 0.77$ \\
\hline 8. Listening to radio/ music & $94(35.1)$ & $30(11.2)$ & $11(4.1)$ & $27(10.1)$ & $25(9.3)$ & $81(30.2)$ & $2.62 \pm 2.14$ \\
\hline $\begin{array}{l}\text { 9. Attending exhibition, cultural } \\
\text { show, performances etc }\end{array}$ & - & - & - & $29(10.8)$ & $42(15.7)$ & $197(73.5)$ & $0.37 \pm 0.67$ \\
\hline Total score $(0-45)$ & & & & & & & $12.50 \pm 3.65$ \\
\hline Leisure Activity & $\begin{array}{l}\text { Everyday } \\
\text { (5) }\end{array}$ & $\begin{array}{l}\text { Almost everyday } \\
\text { (4) }\end{array}$ & $\begin{array}{l}\text { At least once a week } \\
\text { (3) }\end{array}$ & $\begin{array}{l}\text { At least once a month } \\
\text { (2) }\end{array}$ & $\begin{array}{l}\text { Once in several months } \\
\text { (1) }\end{array}$ & $\begin{array}{l}\text { Never } \\
(0)\end{array}$ & Mean \pm SD \\
\hline \multicolumn{8}{|l|}{ Social Activity (SA): } \\
\hline $\begin{array}{l}\text { 1. Meeting or visiting friends or } \\
\text { other family members }\end{array}$ & $29.8(10.8)$ & $26(9.7)$ & $35(13.1)$ & $70(26.1)$ & $53(19.8)$ & $55(20.5)$ & $2.04 \pm 1.59$ \\
\hline $\begin{array}{l}\text { 2. Involve in community activities } \\
\text { (volunteers, association, } \\
\text { politics etc) }\end{array}$ & $1(0.4)$ & $6(2.2)$ & $17(6.3)$ & $29(10.8)$ & $17(6.3)$ & $198(73.9)$ & $0.58 \pm 1.09$ \\
\hline 3. Window shopping & $1(0.4)$ & $1(0.4)$ & $7(2.6)$ & $23(8.6)$ & $17(6.3)$ & $219(81.7)$ & $0.35 \pm 0.82$ \\
\hline $\begin{array}{l}\text { 4. Religious activity (going to } \\
\text { mosque, marhaban class etc.) }\end{array}$ & $58(21.6)$ & $38(14.2)$ & $50(18.7)$ & $31(11.6)$ & $14(5.2)$ & $77(28.7)$ & $2.49 \pm 1.92$ \\
\hline $\begin{array}{l}\text { 5. Having conversations } \\
\text { while relaxing }\end{array}$ & $211(78.7)$ & $28(10.4)$ & $7(2.6)$ & $5(1.9)$ & $13(4.9)$ & $4(1.5)$ & $4.52 \pm 1.14$ \\
\hline Total score $(0-30)$ & & & & & & & $13.12 \pm 4.31$ \\
\hline \multicolumn{8}{|l|}{ Productive Activity (PA): } \\
\hline 1. Cooking/ Baking for pleasure & $6(2.2)$ & $16(6.0)$ & $11(4.1)$ & $22(8.2)$ & $5(1.9)$ & $208(77.6)$ & $0.66 \pm 1.34$ \\
\hline $\begin{array}{l}\text { 2. Rearing or taking care of } \\
\text { pets or domestic animals }\end{array}$ & $30(11.2)$ & $6(2.2)$ & $\cdot$ & $2(0.7)$ & & $230(85.8)$ & $0.66 \pm 1.66$ \\
\hline 3. Gardening & $113(42.2)$ & $25(9.3)$ & $5(1.9)$ & $6(2.2)$ & $1(0.4)$ & $118(44.0)$ & $2.59 \pm 2.37$ \\
\hline $\begin{array}{l}\text { 4. Making handicrafts } \\
\text { (sewing, knitting etc) }\end{array}$ & $5(1.9)$ & $2(0.7)$ & $6(2.2)$ & $24(9.0)$ & $10(3.7)$ & $221(82.5)$ & $0.41 \pm 1.01$ \\
\hline $\begin{array}{l}\text { 5. Cleaning/decorating } \\
\text { housing area }\end{array}$ & $31(11.6)$ & $17(6.3)$ & $6(2.2)$ & $9(3.4)$ & $4(1.5)$ & $201(75.0)$ & $0.98 \pm 1.82$ \\
\hline $\begin{array}{l}\text { 6. Fishing } \\
\text { Total score }(0-30)\end{array}$ & - & $3(1.1)$ & $1(0.4)$ & $6(2.2)$ & $3(1.1)$ & $255(95.1)$ & $\begin{array}{r}0.11 \pm 0.55 \\
5.39 \pm 4.69\end{array}$ \\
\hline
\end{tabular}

Overall, the most frequently reported daily activities were having conversations while relaxing (78.7\%), watching television $(74.6 \%)$, reading $(63.4 \%)$, spending time with grandchildren (42.5\%) and gardening (41.2\%). Meanwhile, for the less popular activities, more than 95\% reported never playing golf; performing musical instruments; playing sports such as tennis or badminton; playing cards; mahjong and others and writing or drawing for pleasure, which are mainly recreational and cognitive activities. Fishing, a productive activity was also not commonly performed by the elderly. They were also more likely to involve in passive and sedentary activities rather than the more vigorous physical activities. Although having conversations while relaxing was the most commonly reported activity, watching television was found to have higher overall mean frequency score compared to all other activities.

\section{Association between current and former leisure participation}

Table 3 shows among the elderly, there were significant associations between current leisure participation and general leisure involvement when they were younger. Recreational physical activity was the only activity which was not significantly influenced by leisure participation while they were younger. However, table 4 shows that only elderly involvement in productive activity was predicted by their leisure involvement at younger age $(B=1.304, p=0.027)$ in the final predictive model. Elderly who participated in any type of leisure while younger will have 1.304 higher score for productive activities. Meanwhile, the level of education of the elderly was found to significantly predict their involvement in recreational, cognitive and social leisure activity. 
Table III. The association between leisure participation while younger and current involvement in recreational, cognitive, social and productive activity of respondents $(n=268)$

\begin{tabular}{|c|c|c|c|c|c|c|c|c|c|c|c|c|c|c|c|c|}
\hline \multirow[t]{2}{*}{ Factor } & \multicolumn{4}{|c|}{$\begin{array}{l}\text { Recreational activity score } \\
(0-20)\end{array}$} & \multicolumn{4}{|c|}{$\begin{array}{l}\text { Cognitive activity score } \\
(0-45)\end{array}$} & \multicolumn{3}{|c|}{$\begin{array}{l}\text { Social activity score } \\
(0-30)\end{array}$} & \multicolumn{5}{|c|}{$\begin{array}{l}\text { Productive activity } \\
\text { score } \\
(0-30)\end{array}$} \\
\hline & Mean & SD & $\mathrm{t}$ & $\mathrm{p}$ & Mean & SD & $\mathrm{t}$ & $\mathrm{p}$ & Mean & SD & $\mathrm{t}$ & $\mathrm{p}$ & Mean & SD & $\mathrm{t}$ & $\mathrm{p}$ \\
\hline \multicolumn{17}{|c|}{$\begin{array}{l}\text { Leisure } \\
\text { participation } \\
\text { while } \\
\text { younger: }\end{array}$} \\
\hline $\begin{array}{l}\text { Yes } \\
\text { No }\end{array}$ & $\begin{array}{l}2.54 \\
2.09\end{array}$ & $\begin{array}{l}3.09 \\
2.65\end{array}$ & -1.27 & 0.207 & $\begin{array}{l}12.90 \\
11.77\end{array}$ & $\begin{array}{l}3.87 \\
3.10\end{array}$ & -2.45 & $0.015^{*}$ & $\begin{array}{l}13.63 \\
12.17\end{array}$ & $\begin{array}{r}4.26 \\
4.27\end{array}$ & -2.68 & $0.008^{*}$ & $\begin{array}{l}5.99 \\
4.28\end{array}$ & $\begin{array}{l}4.93 \\
4.00\end{array}$ & -2.89 & $0.004^{*}$ \\
\hline
\end{tabular}

${ }^{*} p<0.05$

Table IV. Predictive models for leisure activity $(n=268)$

\begin{tabular}{|c|c|c|c|c|c|}
\hline \multirow[t]{2}{*}{ Factor } & \multicolumn{2}{|c|}{ Unstandardized coefficient } & \multirow{2}{*}{$\frac{\text { Standardized coefficient }}{\text { Beta }} \mathrm{t}$} & \multirow{2}{*}{$p$} & \multirow{2}{*}{ Adjusted $\mathrm{R}^{2}$} \\
\hline & B & SE & & & \\
\hline
\end{tabular}

Recreational Activity

Score (RAS)

$\begin{array}{llllll}\text { Constant } & 1.210 & 0.298 & & 4.062 & <0.001 \\ \text { Gender } & 0.833 & 0.352 & 0.142 & 2.367 & 0.019 \\ \text { Education } & 0.809 & 0.384 & 0.128 & 2.109 & 0.036 \\ \text { Locality } & 1.020 & 0.352 & 0.174 & 2.897 & 0.004\end{array}$

Cognitive Activity Score

(CAS)

\begin{tabular}{|c|c|c|c|c|c|}
\hline Constant & 19.334 & 2.596 & & 7.448 & $<0.001$ \\
\hline Age & -0.108 & 0.038 & -0.174 & -2.877 & 0.004 \\
\hline Education & 1.580 & 0.473 & 0.202 & 3.343 & 0.001 \\
\hline
\end{tabular}

0.080

0.0074

Social Activity Score

(SAS)

$\begin{array}{llllll}\text { Constant } & 12.554 & 0.448 & & 28.009 & <0.001 \\ \text { Ethnicity } & -3.458 & 0.544 & -0.362 & -6.353 & <0.001 \\ \text { Marital Status } & 1.681 & 0.534 & 0.182 & 3.150 & 0.002 \\ \text { Education } & 1.276 & 0.535 & 0.138 & 2.387 & 0.018\end{array}$

0.155

Productive Activity

Score (PAS)

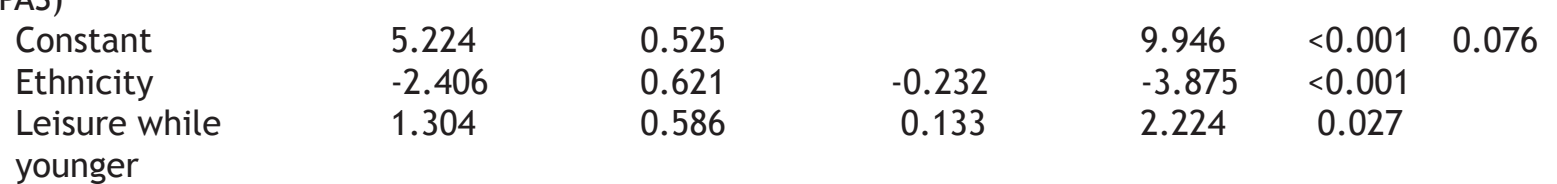

\section{DISCUSSION}

This study showed that social activity was the most frequently performed leisure activities among the elderly. Having conversations while relaxing which was either carried out with family members or friends was found to be the most frequently performed leisure activity on a daily basis compared to other activities.
It is a social activity which is informal and sedentary in nature that mainly involves social interaction. Activities that involve social interaction among elderly were also studied by Triado et al. ${ }^{11}$ They had reported that $43.5 \%$ of the rural elderly in Spain spent time talking to others in an ideal day. However, 
in contrast, the main purpose of the talking was to socialize rather than relaxing. They also reported to allocate less time on passive activities such as watching TV or resting in the ideal day. ${ }^{11}$

Similarly, another study by Silverstein and Parker ${ }^{12}$ reported that social interactions with friends are the most common activity performed during leisure, especially among the very old elderly in Sweden. Although it can be passive and sedentary in nature, studies have shown the various benefits that can be gained from such social activities, even if it only involved simple social interactions or conversations. A critical review by Adams et al. ${ }^{13}$ had suggested that an informal social interaction was the most evident activity affecting the well-being of an individual.

This study also showed that most elderly preferred to participate in cognitive rather than recreational or productive activities. A study by Cheung et al. ${ }^{3}$ also found watching TV was the most prevalent leisure activity among community-dwelling elderly in Hong Kong. Additionally, watching TV was also reported as a major sedentary behavior in the United States. ${ }^{14}$ The high level of involvement in watching TV among the elderly is likely due to the wide availability of television in most households nowadays. Despite the benefits gained from this activity in stimulating the cognitive function and social interaction among the elderly, the sedentary nature of watching TV has been reported to link with several health risks. A study done by $\mathrm{Hu}$ et al. ${ }^{14}$ concluded that sedentary behaviors, especially watching TV were associated with significantly elevated risk of obesity and type 2 diabetes, whereas even light to moderate physical activity was associated with substantially lower risk.

Although it has been reported in previous studies that social and cognitive activities can play a role in reducing the risk of mental-health problems and dementia, the lack of physical activity and the sedentary nature of these activities may also put the elderly at risk of developing debilitating and threatening chronic diseases, that eventually leads to the development of dementia and depression. Since different activities provide different benefits to the elderly, ${ }^{4}$ they should be encouraged to adopt a more active and diverse leisure participation. Those who participated in various and more physical activities reported a better physical well-being. ${ }^{3}$ The findings from this study emphasize the importance of reducing prolonged TV watching and other sedentary behaviors for preventing obesity and diabetes.

Additionally, the low level of leisure participation in recreational physical activity may also indicate the possibility of low level of health awareness and the ineffective promotion of healthy lifestyle in Malaysia, especially among the senior citizens. The important roleplayed byeducational level as a significant predicting factor for cognitive and social activities among the elderly indicates the need to educate them on the importance, values and benefits of leisure.
A comprehensive method of health education, which is elderly friendly and provided in simpler terms is of particular importance to the older persons, especially those with lower education levels. The low involvement of elderly in this study in constructive and stimulating leisure activities such as playing musical instruments, playing cards, chess or mah-jong, using computer or browsing the internet, writing or drawing for fun and also informal teaching may also be related to the low education level among the majority of them.

Despite the high availability of computer and the Internet in each household in Malaysia, the involvement of elderly in using a computer in this study is still considerably low. A study done by Syariffanor ${ }^{15}$ found that there is a correlation between education level and computer usage and also between the level of confidence and computer performance among the elderly in Malaysia. She also suggested that the use of the Internet among senior users (65 and older) is likely to increase in the next decade. As mentioned previously, the lower participation rate in using a computer among the respondents in this study is probably related to the lower educational level and low socioeconomic status or household income among the majority of the elderly.

On the other hand, the high percentage of elderly spending time with their grandchildren is likely to be related to the rising of child-care costs and increasing number of working parents. The increasing cost and difficulty in getting the maid may also contribute to this scenario. This situation indirectly increases the burden of the elderly, as well as prevents them from participating in certain type of leisure activities. The low participation level in physical activities during leisure among the respondents may also be due to their higher involvement in activities which also provides source of income. This was reflected by their higher participation rate in productive activities such as gardening.

No doubt the cultural lifestyle of the multi-racial communities in Malaysia has significantly influenced the leisure activity of the Malaysian elderly. According to Syariffanor, ${ }^{15}$ the Chinese elderly in Malaysia likes to join senior citizens' clubs to socialize while, the Malay elderly, especially those who live in villages participated more in community and religious activities organized by the mosques in their community area. ${ }^{15}$

\section{Association between current and former leisure participation of elderly}

Elderly who were actively participated in leisure activities were also more likely to involve with it when they were younger. Leisure participation while younger was found to influence the elderly interest and desire to be involved in certain type of activities. Very often, they are more likely to be involved and continue doing the same activities that were carried out in their younger days albeit a gradual decline in total time spent as age increases. 
However, due to certain constraints, commitment and life events such as retirement, declining health status and physical function, some elderly had to choose an alternativeleisureactivitytosuit the changing condition. The findings from this study showed that there is a significant continuation between current and former leisure involvement of the elderly in cognitive, social and productive activities. Elderly who were involved in leisure activities when they were younger are more likely to engage in cognitive, social and productive leisure activities. This finding is in accordance with the Continuation Theory of Ageing, which emphasized on the continuity and consistency of patterns of thought, activities, and habits, despite considerable changes in health and social conditions ${ }^{2}$ as individual ages.

Similar finding was also reported by Agahi et al. ${ }^{5}$ involving individuals aged 43 to 99 years old in Sweden, whom were followed for over a 34-year period. Their longitudinal study found that late-life participation was generally preceded by participation earlier in life. They also found that previous participation, both at 10 and 34 years earlier, predicted late-life participation. ${ }^{5}$ In another longitudinal study, Strain et al. ${ }^{16}$ had examined the changes in leisure activities among 380 older adults living in Manitoba, Canada over an 8-year period. They found that watching theater; movies; spectator sports and travel were the activities least likely to be continued over the 8-year period; whilst watching television and reading were most likely to be continued. Their findings were significantly influenced by several factors such as age, gender, education, self-rated health and functional ability. Thus, they concluded that leisure education is an important component for introducing modifications to enhance older adults' participation in desired activities. ${ }^{16}$

As for productive activity, a continuity pattern of involvement at both younger and old age had been reported for gardening. ${ }^{17}$ In addition to walking and bicycling, gardening had contributed substantially to the physical activity pattern of elderly men in Finland, Italy and Netherlands. ${ }^{17}$ According to Goldberg, ${ }^{18}$ individuals must continue lifelong activities as they age and remain engaged socially and professionally, since high activity of a continuous nature correlated well with positive life satisfaction in older adults.

However, our cross-sectional study could not demonstrate the causal relationship between former and current leisure participation of the elderly. Longitudinal studies with larger sample sizes are recommended to further assess the causal relationship by taking into account other relevant factors such as a health status. It is possible that those who came to the clinic were in better health than those who did not or vice versa. There is also a possibility that the elderly who participated in leisure activities was in better health than those who do not.

\section{CONCLUSION}

Active leisure involvement at young age may influence involvement at later life in certain type of activity. Having more knowledge about the leisure activity participation in the elderly is an important starting point when considering specific programmes or service needs of the elderly in our society. Thus, in the process of developing a healthy ageing society, active intervention programmes at young or middle age should be considered and emphasized as an effort to increase and improve leisure participation among the elderly, especially in areas of recreational physical activity.

\section{REFERENCES}

1. Wan Ahmad WI, Ismail Z, Che Mamat CY. Care of the elderly in the Malay culture in Malaysia: Case of rural communities in Kelantan. Malaysian Journal of Social Administration 2003; 2: 81-103.

2. Shetty P. Grey matter: Ageing in developing countries. Lancet 2012; 379:1285-7.

3. Cheung MC, Ting W, Chan LY, Ho KS, Chan WM. 2009. Leisure participation and health-related quality of life of community dwelling elders in Hong Kong. Asian Journal of Gerontology and Geriatrics 2009; 4:15-23.

4. Menec $\mathrm{VH}$. The relation between everyday activities and successful aging: a 6-year longitudinal study. J Gerontol B Psychol Sci Soc Sci 2003; 58:S74-82.

5. Agahi N, Ahacic K, Parker MG. Continuity of leisure participation from middle age to old age. J Gerontol B Psychol Sci Soc Sci 2006; 61:S340-6.

6. Onega LL, Tripp-Reimer T. Expanding the scope of continuity theory: Application to gerontological nursing. J Gerontol Nurs 1997; 23:29-35.

7. Atchley RC. A continuity theory of normal aging. Gerontologist 1989; 29:183-90.

8. Horowitz BP, Vanner E. Relationships among active engagement in life activities and quality of life for assisted-living residents. Journal of Housing for the Elderly 2010; 24:130-50.

9. Bevil CA, O'Connor PC, Mattoon PM. Leisure activity, life satisfaction, and perceived health status in older adults. Gerontology \& Geriatrics Education 1994; 14:3-19.

10. Armstrong GK, Morgan K. Stability and change in levels of habitual physical activity in later life. Age Ageing 1998; 27:17-23.

11. Triado C, Villar F, Sole C, Celdran M, Osuna MJ. Daily activity and life satisfaction in older people living in rural contexts. Span J Psychol 2009; 12:236-45.

12. Silverstein $M$, Parker MG. Leisure activities and quality of life among the oldest old in Sweden. Research on Aging 2002; 24:528-47.

13. Adams KB, Leibbrandt S, Moon H. A critical review of the literature on social and leisure activity and wellbeing in later life. Ageing Soc 2011; 31:683712. 
14. Hu FB, Li TY, Colditz GA Willet WC, Manson JE. Television watching and other sedentary behaviors in relation to risk of obesity and type 2 diabetes mellitus in women. JAMA 2003; 289: 1785-91.

15. Syariffanor $\mathrm{H}$. Localizing the user interface for elderly people in Malaysia. Thesis submitted for MSc. Multimedia Technology 2007. York, United Kingdom: Department of Computer Science, University of York. [unpublished]

16. Strain LA, Grabusic CC, Searle MS, Dunne MJ. Continuing and ceasing leisure activities in later life: a longitudinal study. Gerontologist 2002; 42:217-23.

17. Bijnen FCH, Feskens EJM, Caspersen CJ, et al. Physical activity and cardiovascular risk factors among elderly men in Finland, Italy, and the Netherlands. Am J Epidemiol 1996; 143:553-61.

18. Goldberg E. A healthy retirement. AORN J 2002; 76:873-4. 